\title{
KUALITAS DAN KEAMANAN LULUR BERBASIS HERBAL PRODUKSI UKM RENATA DI KOTA PONTIANAK
}

\author{
QUALITY AND SAFETY OF NATURAL BODY SCRUB \\ PRODUCED BY RANATA SMES IN PONTIANAK
}

\author{
Heru A. Cahyanto dan Asmawit \\ Balai Riset dan Standardisasi Industri Pontianak Jl. Budi Utomo No 41 Pontianak \\ Email : heru-a@kemenperin.go.id
}

Received : 27/07/2017; revised : 25/08/2017; accepted : 04/09/2017

Published online : 29/12/2017

\begin{abstract}
ABSTRAK
Penelitian tentang lulur produksi usaha kecil mikro/UKM Ranata Kosmetik dilakukan untuk mengetahui kualitas lulur dan keamanannya. Lulur produksi UKM Ranata menggunakan bahan bahan alami atau herbal sebagai bahan bakunya. Bahan yang digunakan antara lain buah alpukat, daun teh hijau, buah strawberry, bengkoang dan aneka bahan rempah-rempah. Produk lulur diuji kualitas di Laboratorium Balai Riset dan Standardisasi Industri Pontianak dan LPPT UGM Yogyakarta. Hasil uji dibandingkan dengan pustaka dan peraturan yang diacu. Hasil uji lulur Ranata kosmetik berupa kadar air 9,6621\%-14,5430\%, kadar abu total 0,3258\%- 8,5890\%, ALT 25 $\mathrm{kol} / \mathrm{gr}-2,6 \times 10^{2} \mathrm{kol} / \mathrm{gr}, \mathrm{AKK}<10 \mathrm{kol} / \mathrm{gr}-1 \times 10^{1} \mathrm{koloni} / \mathrm{gr}$ serta ukuran partikel yang bervariasi. Sementara bahan berbahaya dan dilarang dalam lulur tidak ditemukan atau negatif.
\end{abstract}

Kata kunci : lulur, kualitas, herbal

\begin{abstract}
The Research on the production of small and micro enterprises/SMEs Ranata Cosmetic has been done to determine the quality of scrub and its safety. Body scrub production of Ranata SME using natural ingredients as raw materials. The materials used include avocado, green tea leaves, strawberry fruit, bengkoang and various spices. Scrubs were tested its quality in Laboratory Research Center and Industrial Standardization of Pontianak and LPPT UGM Yogyakarta. The results were compared with the references and regulations. The results test of water content ie $9.6621 \%$ to $14.5430 \%$, TPN $25 \mathrm{col} / \mathrm{gr}-2,6 \times 10^{2} \mathrm{col} / \mathrm{gr}$, yeast $<10 \mathrm{col} / \mathrm{gr}-1 \times 10^{1} \mathrm{col} / \mathrm{gr}$ and varies in size of particle. While hazardous and prohibited ingredients were not found or negative
\end{abstract}

Key word : Scrub, quality, herbs

\section{PENDAHULUAN}

Dalam beberapa tahun terakhir banyak sekali bermunculan produsen kosmetik herbal skala industri rumah tangga yang menggunakan bahan baku bahan alami. Industri kosmetik rumah tangga dengan berbagai jenis dan produk mampu mengisi kebutuhan masyarakat yang selama ini pasarnya banyak diambil oleh perusahaan besar kosmetika seperti Martha Tilaar, Unilever, Mustika Ratu dan lain-lain.

Menurut sifat dan pembuatan kosmetik dibagi menjadi kosmetik modern dan kosmetik tradisional. Kosmetik modern dibuat dengan bahan kimia dan dioleh secara modern. Kosmetik tradisional diibuat menggunakan bahan benar-benar tradisional atau alami dan menggunakan resep warisan secara turun temurun (Tranggono dan Latifah 2007). Industri kosmetik besar banyak mengambil pasar kosmetik modern, sementara kosmetik tradisional oleh industri kecil juga skala rumah tangga.

Kosmetik tradisional menggunakan bahan-bahan herbal sebagai bahan aktif dalam sediaan kosmetik. Bahan herbal yang digunakan dapat berupa bentuk mentah atau ekstrak. Kosmetik herbal banyak digunakan karena keamanan dan efek samping yang minimal terhadap kulit selain memberi nutrisi yang diperlukan oleh kulit (Joshi dan Pawar 2005). Khasiat bahan herbal terutama aktivitas antioksidan terutama sepertti bahan temutemuan atau rempah (Rachman dkk 2008).

Bahan-bahan kosmetik tradisional seperti rempah-rempah atau bahan tradisional lain dikeringkan menggunakan sinar matahari atau menggunakan alat pengering buatan. Apabila pengeringan dilakukan dengan sinar matahari, proses pengeringan ditutup dengan kain hitam untuk mempercepat pengeringan. Sementara keuntungan menggunakan pengering 
buatan adalah cepat, suhu konstan/dapat diatur dan efisien.

Salah satu rempah yang sering digunakan adalah kunyit. Fungsi kunyit dalam kosmetik lulur adalah untuk menghaluskan dan memberi warna kuning langsat (Said 2003). Kunyit sering digunakan sebagai bahan pemberi warna kuning langsat. Kunyit dapat diambil ekstrak atau langsung digunakan sebagai scrub. Ekstrak kunyit dapat ditambahkan tepung beras atau serbuk rimpang kunyit langsung digunakan sebagau scrub. Untuk bahan berupa rempah atau herbal yang dihaluskan dapat sekaligus berfungsi sebagai scrub.

Scrub yang dibuat dari tepung beras yang digerus kasar sesuai ukuran mesh yang diinginkan (Yuliati dan Binarjo 2010). Dapat juga digunakan dari bahan lain dari biji yang digerus dan diayak. Sebagai contoh biji pinang (Sulistianingrum 2014). Biji pinang dapat dijadikan scrub dengan mengeringkan. Menggerus dan mengayak sesuai ukuran scrub yang diinginkan. Scrub bersifat abbrasive untuk menghilangkan kulit mati dan memberikan kesan lembut dan segar pada kulit (Nemade dan Baste 2014).

Usaha Kecil Mikro kosmetik di
Pontianak mulai banyak berkembang memanfaatkan bahan alam yang tersedia. Disamping menggunakan bahan mentah berupa bagian tanaman yang dikeringkan juga menggunakan bentuk ekstrak. Salah satu Usaha Kecil Mikro kosmetika di Kota Pontianak adalah Ranata. Ranata Kosmetik, selain sebagai usaha salon kecantikan juga memproduksi lulur sesuai pesanan pelanggan. Pesanan pelanggan diantaranya dari Pulai Bali, yang banyak membutuhkan produk kosmetik guna mendukung industri pariwisatanya.

Kurangnya pengetahuan masyarakat dalam pembuatan kosmetik yang baik kadang dengan sengaja menggunakan bahan kosmetik yang tidak aman. Sebab lain adalah karena keinginan masyarakat yang ingin cepat mendapatkan manfaat dari kosmetik yang digunakan. Sebagai contoh adanya bahan kimia merkuri dan hodroquinon dalam produk kosmetik yang tidak sesuai. Tujuan penelitian ini adalah untuk mengevaluasi kualitas dan keamanan produk lulur kosmetik produksi UKM Ranata Kosmetik dari Kota Pontianak. Walaupun produksi menggunakan bahan-bahan alami namun tentu harus ada kontrol produksi untuk memastikan keamanan, sehingga produk yang dihasilkan memenuhi standar kualitas dan keamanan serta tidak merugikan konsumen. Selain itu dapat digunakan sebagai bahan evaluasi mutu produk untuk dapat digunakan sebagai acuan dalam peningkatan mutu produk lulur yang dihasilkan. Adapun tujuan dilakukan penelitian ini adalah untuk menentukan kualitas dan keamanan kosmetik lulur produksi UKM Ranata di Kota Pontianak

\section{BAHAN DAN METODE}

Bahan-bahan yang digunakan adalah lulur kosmetik produksi UKM Ranata yaitu lulur tradisional jenis : alpukat, green tea, strawberry, rempah, bengkoang

Alat-alat yang digunakan dalam penelitian adalah oven, atomic absorbtion spectroscopy, analitical balance, ayakan no 30200.

Pengujian dilakukan berupa : Kadar air, kadar abu, cemaran mikroba, cemaran logam berat. Kadar air dan abu dilakukan menggunakan oven dengan metode SNI 013181-1992.

Cemaran mikroba dilakukan uji di Laboratorium mikrobiologi berupa nilai angka lempeng total dan angka kapang khamir. Cemaran logam berat menggunakan alat AAS. Nilai ALT dan AKK mengacu pada peraturan Kepala Badan POM Nomor HK.03.1.23.07.11.6662 Tahun 2001 tentang persyaratan cemaran mikroba dan logam berat dalam kosmetika.

\section{HASIL DAN PEMBAHASAN}

Ranata kosmetik membuat lulur dengan bahan-bahan alami yang diformulasikan dalam formula lulur seperti pada tabel 1.

Tabel 1. Organoleptik Lulur Ranata Kosmetik

\begin{tabular}{ll}
\hline Jenis lulur & \multicolumn{1}{c}{ Organoleptik } \\
\hline Lulur Alpukat & Serbuk halus berbutir bau khas ekstrak alpukat \\
Lulur Green tea & Serbuk halus berbutir bau khas ekstrak green tea \\
Lulur Strawberry & Serbuk halus berbutir bau khas ekstrak strawberry \\
Lulur Rempah & Serbuk berbutir kasar bau khas rempah-rempah \\
Lulur Bengkoang & Serbuk halus berbutir bau khas bengkoang \\
\hline
\end{tabular}

Lulur kosmetik Ranata menggunakan bahan-bahan alami sebagai bahan bakunya. Uji organoleptik terhadap lulur sesuai dengan karakteristik bahan awal yang digunakan. Lulur alpukat memiliki bau dan rasa khas buah alpukat, warna hijau kekuningan. Lulur Green tea memiliki rasa sedikit pahit warna hijau cerahgelap. Lulur strawberry memiliki warna merah 
muda, rasa dan bau manis khas. Lulur bengkoang Memiliki warna putih dan rasa, bau lemah sementara lulur rempah memiliki rasa, bau khas rimpang serta warna putih kecoklatan. Partikel lulur menentukan kualitas lulur. Jika lulur terlalu kasar maka akan kurang baik dalam aplikasi sementara jika terllu halus akan melekat dalam kulit (Yuliati dan Binarjo 2010). Hasil pengujian dengan ayakan didapatkan distribusi ukuran partikel beragam pada beberapa jenis lulur seperti pada tabel 2.

Tabel 2. Distribusi Ukuran Partikel Lulur Ranata Kosmetik

\begin{tabular}{cccccc}
\hline No Ayakan & Lulur alpukat & $\begin{array}{c}\text { Lulur green } \\
\text { tea }\end{array}$ & $\begin{array}{c}\text { Lulur } \\
\text { strawberry }\end{array}$ & $\begin{array}{c}\text { Lulur } \\
\text { rempah }\end{array}$ & $\begin{array}{c}\text { Lulur } \\
\text { bengkoang }\end{array}$ \\
\hline 30 & $0,09 \%$ & $9,60 \%$ & $0,05 \%$ & $28,41 \%$ & $9,81 \%$ \\
40 & $28,81 \%$ & $14,62 \%$ & $6,08 \%$ & $15,11 \%$ & $14,42 \%$ \\
60 & $15,92 \%$ & $16,99 \%$ & $39,29 \%$ & $22,46 \%$ & $18,30 \%$ \\
70 & $3,18 \%$ & $3,36 \%$ & $8,26 \%$ & $6,91 \%$ & $9,92 \%$ \\
100 & $4,48 \%$ & $5,00 \%$ & $11,76 \%$ & $16,47 \%$ & $10,40 \%$ \\
200 & $28,49 \%$ & $37,02 \%$ & $15,32 \%$ & $10,33 \%$ & $37,01 \%$ \\
Sisa & $19,00 \%$ & $13,38 \%$ & $19,22 \%$ & $0,28 \%$ & $0,10 \%$ \\
Scrub & $28,90 \%$ & $24,22 \%$ & $6,13 \%$ & $43,52 \%$ & $24,23 \%$ \\
\hline
\end{tabular}

Kualitas lulur juga terlihat pada uji kosmetik lulur diuji berupa kadar air, kadar abu, ALT dan AKK. Kadar air menentukan daya simpan lulur. Kadar air diatas $10 \%$ akan mudah ditumbuhi jamur dan mikroba. Kadar abu tiap bahan dan produk berbeda-beda sehingga dapat menentukan kemurnian bahan. Kadar abu juga dapat mengindikasikan kontaminan pada produk. Kadar abu lulur berbahan rempah paling tinggi karena tidak menggunakan bahan ekstrak seperti bahan lulur lainnya. Hasil uji terlihat pada tabel 3.

Tabel 3. Hasil Uji Kadar Air, Kadar Abu, ALT dan AKK

\begin{tabular}{lccccc}
\hline Parameter & L.alpukat & L.green tea & L.strawberry & L.rempah & L.bengkoang \\
\hline Kadar air & $10,9170 \%$ & $10,6102 \%$ & $9,6621 \%$ & $14,5430 \%$ & $11,0839 \%$ \\
Kadar abu & $0,6900 \%$ & $0,7723 \%$ & $0,3258 \%$ & $8,5890 \%$ & $0,9954 \%$ \\
ALT & $<25 \mathrm{kol} / \mathrm{gr}$ & $<25 \mathrm{kol} / \mathrm{gr}$ & $<25 \mathrm{kol} / \mathrm{gr}$ & $2,6 \times 10^{2} \mathrm{kol} / \mathrm{gr}$ & $<25 \mathrm{kol} / \mathrm{gr}$ \\
$\mathrm{AKK}$ & $1 \times 10^{1} \mathrm{ko} / \mathrm{gr}$ & $<10 \mathrm{kol} / \mathrm{gr}$ & $1,5 \times 10^{1} \mathrm{kol} / \mathrm{gr}$ & $1 \times 10^{1} \mathrm{kol} / \mathrm{gr}$ & $<10 \mathrm{kol} / \mathrm{gr}$ \\
\hline
\end{tabular}

Produk serbuk lulur sangat rentan terhadap kontamnasi mikroba. Cemaran mikroba dapat menyebabkan kerusakan kosmetik lulur. Cemaran dapat berasal dari air, bahan baku maupun ruang tempat pembuatan. Pencemaran terutama akibat jamur karena Indonesia memiliki iklim tropis dengan kelembaban yang tinggi (Mariana dkk 2004). Cemaran logam terutama logam berat juga mengindikasikan keamanan kosmetik yang digunakan. Logam berat merupakan senyawa yang secara alami ditemukan dalam tanah, air

Tabel 4. Hasil Uji Cemaran Logam

\begin{tabular}{|c|c|c|c|c|c|}
\hline Jenis Iulur & $\begin{array}{c}\text { Kadar } \\
\text { Pb/ppm }\end{array}$ & $\begin{array}{c}\text { Kadar } \\
\text { Cd/ppm }\end{array}$ & $\begin{array}{l}\text { Kadar } \\
\text { Hg/ppm }\end{array}$ & $\begin{array}{c}\text { Kadar } \\
\text { As/ppm }\end{array}$ & $\begin{array}{c}\text { Kadar } \\
\text { Cu/ppm }\end{array}$ \\
\hline \multirow[t]{2}{*}{ Lulur alpukat } & $<0,04$ & $<0,02$ & $<0,004$ & $<0,001$ & $<0,002$ \\
\hline & $<0,04$ & $<0,02$ & $<0,004$ & $<0,001$ & $<0,002$ \\
\hline \multirow[t]{2}{*}{ Lulur green tea } & $<0,04$ & $<0,02$ & $<0,004$ & $<0,001$ & $<0,002$ \\
\hline & $<0,04$ & $<0,02$ & $<0,004$ & $<0,001$ & $<0,002$ \\
\hline \multirow[t]{2}{*}{ Lulur starberry } & $<0,04$ & $<0,02$ & $<0,004$ & $<0,001$ & $<0,002$ \\
\hline & $<0,04$ & $<0,02$ & $<0,004$ & $<0,001$ & $<0,002$ \\
\hline \multirow[t]{2}{*}{ Lulur rempah } & $<0,04$ & $<0,02$ & $<0,004$ & $<0,001$ & $<0,002$ \\
\hline & $<0,04$ & $<0,02$ & $<0,004$ & $<0,001$ & $<0,002$ \\
\hline \multirow[t]{2}{*}{ Lulur bengkoang } & 3,74 & $<0,02$ & $<0,004$ & $<0,001$ & $<0,002$ \\
\hline & 3,76 & $<0,02$ & $<0,004$ & $<0,001$ & $<0,002$ \\
\hline
\end{tabular}

yang memungkinkan ada dalam bahan bahan produk kosmetik. Namun untuk merkuri, senyawa ini sering digunakan sebagai bahan dalam krim pemutih. Oleh karena itu pengujian terhadap kandungan cemaran logam berat terutama merkuri sangat penting dalam hal keamana kosmetik. Merkuri beresiko terhadap perempuan yang mengandung atau menyusui, karena dapat menyebabkan keracunan pada bayi ataupun kecacatan pada janin (Al-Saleh 2016). Hasil uji cemaran logam dalam kosmetik lulur seperti pada tabel 4. 
Salah satu bahan yang dilarang dalam kosmetik antara lain merkuri, hidroquinon, asam retinoat, juga zat warna sintetis seperti rhodamin $\mathrm{B}$ dan merah K3. Bahan tersebut dilarang berdasarkan peraturan Menkes RI No.445/MENKES/PER/V/1998. Dalam uji Ranata Kosmetik dilakukan uji terhadap hidroquinon. Hidroquinon digunakan sebagai bahan untuk mencerahkan kulit. Namun senyawa ini banyak menimbulkan efek samping yang tidak dikehendaki seperti iritasi kulit, rasa terbakar. Selain itu hidroquinon dapat menyebabkan kelainan ginjal, kanker darah dan sel hati. Penggunaan hidroquinon dalam kosmetik dibatasi sampai $2 \%$. Kelebihan dapat menyebabkan oochronosis. Ooochronosis adalah kulit berbintil dan berwarna coklat kebiruan dengan rasa panas dan gatal. Dalam kosmetik Ranata uji terhadap hidroquinon yang dilakukan di LPPT UGM adalah negatif artinya tidak ditemukan senyawa hidroquinon dalam sediaan produk lulur Ranata. Uji terhadap bahan yang dilarang berupa hidroquinon seperti terlihat pada tabel 5 .

Tabel 5. Hasil Uji Hidroquinon

\begin{tabular}{lccc}
\hline \multicolumn{1}{c}{ Nama lulur } & Parameter uji & Metode & Hasil \\
\hline Lulur alpukat & Hidroquinon & KLT & Negatif \\
Lulur green tea & Hidroquinon & KLT & Negatif \\
Lulur starberry & Hidroquinon & KLT & Negatif \\
Lulur rempah & Hidroquinon & KLT & Negatif \\
Lulur bengkoang & Hidroquinon & KLT & Negatif \\
\hline
\end{tabular}

\section{KESIMPULAN}

Produk lulur kosmetik produksi UKM Ranaka memiliki nilai kadar air dalam rentang 9,6621\%-14,5430\%, kadar abu total 0,3258\%$8,5890 \%$, ALT $25 \mathrm{kol} / \mathrm{gr}-2,6 \times 10^{2} \mathrm{kol} / \mathrm{gr}$, AKK $<10 \mathrm{kol} / \mathrm{gr}-1 \times 10^{1} \mathrm{koloni} / \mathrm{gr}$. Keragaman ukuran partikel terutama untuk scrub belum terstandar, perlu proses pengayakan sesuai ukuran yang diinginkan. Tidak ditemukan adanya cemaran logam berat dan tidak ditemukan bahan berbahaya dan dilarang dalam produk lulur Ranata Kosmetik

\section{DAFTAR PUSTAKA}

Al-Saleh, I. 2016. Potential health consequences of applying mercury-containing skinlightening creams during pregnancy and lactation periods. International Journal of Hygiene and Environmental Health. 219 (4) : 468-474

Joshi, L. S., and Pawar, H. A. 2015. Herbal cosmetics and cosmeceuticals: An overview. Natural Products Chemistry \& Research 3: 170 doi: 10.4172/23296836.1000170

Mariana dkk. 2004. Gambaran Cemaran Jamur Pada Kosmetik Bedak Bayi dan Bayangan Mat. Media Litbang Kesehatan 14 (4) :1-6

Mayasari, F. 2014. Uji Cemaran jamur pada lulur tradisional yang beredar di Kota Gorontalo. Disertasi. Universitas Negeri Gorontalo
Nemade, C.T., and Baste, N. 2014. Formulation and evaluation of a herbal facial scrub. World Journal of Pharmaceutical Research. 3 (3) : 4367-4371

Rachman et al. 2008. Aktivitas antioksidan ekstrak tunggal dan kombinasinya Dari tanaman curcuma sp. Jurnal ilmu kefarmasian Indonesia. 6 (2) : 69-74.

Said, A. 2003. Khasiat dan manfaat kunyit. Ganeca Exacta.

Sulistianingrum, Fitriana, dan M. Kes Maspiyah. 2014. Pengaruh perbedaan persentase tepung biji buah pinang terhadap kualitas sediaan masker kulit wajah berbahan dasar tepung beras sebagai kosmetika tradisional. Jurnal Mahasiswa Teknologi Pendidikan 3 (2) : 16-22.

Tranggono, R. I dan Latifah, L. 2007. Buku Pegangan : Ilmu Pengetahuan Kosmetik. Gramedia Pustaka Utama

Yuliati, E., dan Binarjo, A. 2010. Pengaruh ukuran partikel tepung beras terhadap daya angkat sel kulit mati lulur bedak dingin. Dalam : Prosiding Konggres IImiah XVIII dan Rapat Kerja Nasional Ikatan Apoteker Indonesia 